\title{
Simvastatin increases cell viability and suppresses the expression of cytokines and vascular endothelial growth factor in inflamed human dental pulp stem cells in vitro
}

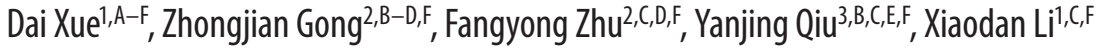 \\ ${ }^{1}$ Department of Stomatology, Wuxi Children's Hospital, Nanjing Medical University, China \\ ${ }^{2}$ Department of Stomatology, Wuxi People's Hospital, Nanjing Medical University, China \\ ${ }^{3}$ Department of Stomatology, Pudong New Area People's Hospital, Shanghai, China \\ A - research concept and design; $\mathrm{B}$ - collection and/or assembly of data; $\mathrm{C}$ - data analysis and interpretation; \\ $D$ - writing the article; $E$ - critical revision of the article; $F$ - final approval of the article
}

Address for correspondence

Dai Xue

E-mail:Z_BJ2014@163

Funding sources

None declared

Conflict of interest

None declared

Received on May 12,2017

Reviewed on June 16, 2017

Accepted on July 10, 2017

\begin{abstract}
Background. In recent years, simvastatin has been demonstrated to be capable of inducing odontogenic differentiation in human dental pulp stem cells (DPSCs), which makes it a promising source for endodontic treatment in pulpitis. However, a comprehensive understanding of how simvastatin affects the behavior of DPSCs and its potential in pulpitis is still lacking.
\end{abstract}

Objectives. In this study, we investigated the effects of simvastatin on the viability of inflamed DPSCS. The expression of cytokines and vascular endothelial growth factor (VEGF) was also studied in response to simvastatin treatment.

Material and methods. We characterized the cell viability, inflammatory reactions and the production of VEGF in inflamed DPSCs, induced by lipopolysaccharides (LPS). The methylthiazolyldiphenyl-tetrazolium bromide (MTT) assay, cell cycle, apoptosis analysis, quantitative reverse transcription polymerase chain reaction (RT-PCR), enzyme-linked immunosorbent assay (ELLSA), and western blot analyses were performed.

Results. We observed that a low dosage of simvastatin accelerated cell proliferation, whereas its high dosage (>15 $\mathrm{gg} / \mathrm{mL}$ ) suppressed propagation. A simvastatin dose of $8 \mu \mathrm{g} / \mathrm{mL}$ was sufficient to promote cell growth and cell cycle progression in DPSCs treated with LPS. Meanwhile, simvastatin induced apoptosis. The expression of multiple cytokines, including interleukins (IL)-1, IL-4 and IL-18, and especially interferon-gamma (IFN- - ) and tumor necrosis factor-alpha (TNF-a), was significantly suppressed. Moreover, the protein secretion and mRNA transcription of VEGF was observed to be markedly inhibited by simvastatin by inactivating mitogen-activated protein kinase (MAPK) signaling.

Conclusions. Taken together, these results suggested that simvastatin might be a potent ingredient to enhance cell proliferation, alleviate inflammation response and attune vasculogenesis in pulpitis.

Key words: cytokines, vascular endothelial growth factor, simvastatin, dental pulp stem cell, pulpitis

DOI

10.17219/acem/75776

Copyright

Copyright by Author(s)

This is an article distributed under the terms of the

Creative Commons Attribution Non-Commercial License

(http://creativecommons.org/licenses/by-nc-nd/4.0/) 


\section{Introduction}

Pulpitis is a quite commonly occurring inflammation in the dental pulp tissue, which is characterized by increased sensitivity to stimuli, specifically hot and cold stimuli. ${ }^{1}$ Following the inflammation, some fundamental alterations have also been reported, such as an increase in blood flow, enhanced capillary permeability, the diffusion of vascular fluid into intercellular spaces, and the immigration of granulocytes and monocytes. ${ }^{2}$ Tissue injury caused by trauma, bacterial infection, chemical substances, contusion, etc. is the main cause of pulpitis. ${ }^{3}$ The correlation between the invasion of Gram-negative bacteria and their product, lipopolysaccharides (LPS), and the symptoms of pulpitis has been investigated. ${ }^{4,5}$

The dental pulp contains connective tissue, lymphatic tissues, blood vessels, neural fibers, and dental pulp stem cells (DPSCs), and its main functions are to produce dentin and to maintain the biological and physiological vitality of the dentin. ${ }^{6,7}$ Within the dental pulp, DPSCs provide a promising source of cells for applications in regenerative medicine. By their nature, DPSCs have the potential through the production of odontoblasts to create reparative dentin in response to injury. ${ }^{8}$ Although DPSCs comprise only $1 \%$ of the total cell population of the pulp, they play crucial roles in the process of dentin regeneration in both acute and chronic pulpitis., ${ }^{9,10}$

In pulpitis, oral antibiotics having bacteriostatic or bactericidal properties are widely used to control or eliminate the attacking bacteria. ${ }^{11}$ However, systematic antibiotics showed poor outcomes in some cases of pulpitis. ${ }^{12}$ In regard to regenerative medicine, DPSCs demonstrated strong potential to regenerate the dentin with the aid of recombinant human bone morphogenetic protein $2 .{ }^{13,14}$ In recent years, a lipid-lowering medication, simvastatin, has been demonstrated to be capable of inducing odontogenic differentiation of human DPSCs in vitro and in vivo, and of promoting pulp regeneration. ${ }^{15-17}$ Until now, studies on how simvastatin affects DPSCs have been limited. In this study, we investigated the effects of simvastatin on the viability of inflamed DPSCs, and the underlying mechanism.

\section{Material and methods}

\section{Isolation and culture of dental pulp stem cells}

Six impacted $3^{\text {rd }}$ molars were removed by an oral surgeon from 5 teenage subjects with irreversible pulpitis. Dental pulp stem cells were isolated as previously described.$^{18}$ Briefly, the dental pulp was harvested and immersed in $\alpha$-modified minimal essential medium ( $\alpha$-MEM) (Sigma-Aldrich, Burlington, USA) containing $3 \mathrm{mg} / \mathrm{mL}$ of type I collagenase and $4 \mathrm{mg} / \mathrm{mL}$ of dispase at $37^{\circ} \mathrm{C}$ for $1 \mathrm{~h}$. After enzymatic disaggregation, the pulp was dissociated and the cell suspension was then plated in a $25 \mathrm{~cm}^{2} \mathrm{flask}$, and maintained in Iscove modified Dulbecco medium (IMDM) (Thermo Fisher Scientific, Waltham, USA), supplemented with $10 \%$ fetal calf serum (FCS) (Gibco, New York, USA), $2 \mathrm{mM}$ of L-glutamine, $100 \mathrm{U} / \mathrm{mL}$ of streptomycin, and $100 \mathrm{U} / \mathrm{mL}$ of cell colony formed on approx. day 7 . Then, it was picked, resuspended and plated in a new flask. Dental pulp stem cells were expanded upon reaching 70\% confluency for further study. The study was approved by the Ethics Committee of Wuxi Children's Hospital (China) and written informed consent was obtained from all the enrolled subjects and their parents before admittance to the study.

\section{Cell viability assay}

To test the effect of simvastatin on cell proliferation, DPSCs were cultured in 96-well plates, in media containing various concentrations, ranging from 0 to $20 \mu \mathrm{g} / \mathrm{mL}$ $(0,2,4,8,10,15$, and $20 \mu \mathrm{g} / \mathrm{mL})$. Additionally, cell viability in LPS challenging conditions was also measured by randomly assigning the cells into the control group (not treated), the simvastatin $(8 \mu \mathrm{g} / \mathrm{mL})$ group, an LPS $(60 \mu \mathrm{g} / \mathrm{mL})$ group, and an LPS + simvastatin group. Cell viability was measured by using methylthiazolyldiphenyl-tetrazolium bromide (MTT) purchased from Thermo Fischer Scientific (Waltham, USA). Following exposure to simvastatin or LPS, $10 \mu \mathrm{L}$ of MTT solution $(5 \mathrm{mg} / \mathrm{mL}$ ) was added to each well, and the plates were incubated for $3 \mathrm{~h}$ at $37^{\circ} \mathrm{C}$. After removing the medium, the formazan was dissolved in $200 \mu \mathrm{L}$ of dimethyl sulfoxide (DMSO) (Sigma-Aldrich) in each well. Absorbance was read at $5 \mathrm{~nm}$ using a microplate reader (Bio-Rad Laboratories, Hercules, USA).

\section{Cell cycling analysis}

The DNA contents of each cell cycle phase was reflected by variations in the propidium iodide (PI) fluorescence intensities, and the distribution of cell cycle phases was analyzed by flow cytometry following PI staining as previously described. ${ }^{19}$ In brief, DPSCs were washed with ice-cold phosphate-buffered saline (PBS), suspended in approx. $0.5 \mathrm{~mL}$ of $70 \%$ cold ethanol and kept at $4^{\circ} \mathrm{C}$ for $30 \mathrm{~min}$. The cells were subsequently treated with $100 \mathrm{mg} / \mathrm{mL}$ of DNase-free RNase (Sigma-Aldrich) and incubated for $30 \mathrm{~min}$ at $37^{\circ} \mathrm{C}$ prior to the addition of PI (50 mg/mL; Sigma-Aldrich) directly into the cell suspension. The suspension was filtered through a $50 \mathrm{~mm}$ nylon mesh, and a total of 10,000 stained cells were subjected to flow cytometric analysis (FACSCalibur; BD Biosciences, San Jose, USA).

\section{Assessment of apoptosis}

Dental pulp stem cells were stained with an Annexin V-FITC apoptosis detection kit (Sigma-Aldrich) to determine whether the cells underwent apoptosis. Propidium 
iodide staining was used as a control to differentiate cells undergoing necrosis. Dental pulp stem cells were seeded in tissue culture slides and allowed to attach for $24 \mathrm{~h}$. Subsequently, the cells were resuspended in $500 \mu \mathrm{L}$ of binding buffer, $5 \mu \mathrm{L}$ of Annexin V-FITC and $5 \mu \mathrm{L}$ of PI were added, and the cells were incubated for $5 \mathrm{~min}$ at $37^{\circ} \mathrm{C}$ in the dark. Flow cytometry analysis was performed to evaluate the apoptosis of DPSCs. Three independent trials were conducted.

\section{Analysis of expression of cytokine genes}

Quantitative real-time PCR (qPCR) was performed to quantify the expression of interleukin $(I L)-1, I L-4, I L-6$, $I L-1 \beta$, interferon-gamma $(I F N-\gamma)$ and tumor necrosis factor-alpha $(T N F-\alpha)$. Dental pulp stem cells were lysed with TRIzol reagent (Thermo Fischer Scientific) and the total RNA was extracted. Afterwards, cDNA was synthesized using a PCR kit (Becton-Dickinson, Franklin Lakes, USA). In the quantification of mRNA expression, $1 \mu \mathrm{L}$ of $\mathrm{cDNA}$ was applied on an ABI 7500 real-time machine (ABI, Camarillo, USA), using a SYBR Green reagent (Takara Bio, Kusatsu, Japan). The primer pairs are listed in Table 1. Glyceraldehyde 3-phosphate dehydrogenase (GAPDH) was employed as an internal control and used for the normalization of cycle threshold $(\mathrm{Ct})$ values. Experiments were carried out in triplicate.

\section{Enzyme-linked immunosorbent assay for vascular endothelial growth factor secretion}

An enzyme-linked immunosorbent assay (ELISA) kit (R\&D Systems, Minneapolis, USA) was used to quantify the vascular endothelial growth factor (VEGF) concentration in the medium, strictly following the manufacturer's instructions. Briefly, standards and samples were diluted on 96 -well plates, and $50 \mu \mathrm{L}$ of conjugate solution was added to each well. After incubation at room temperature for $2 \mathrm{~h}$, the wells were washed with PBS solution 3 times. Then, $200 \mu \mathrm{L}$ of substrate solution was added. The plate was incubated for 10-15 min and the color development was stopped. The absorbance of each well was determined at $450 \mathrm{~nm}$ in a microplate reader (BioTeke, Beijing, China). A standard curve was constructed by plotting the absorbance of standards against the known concentration. The VEGF concentration was deduced from the standard curve.

\section{Western blot analysis for mitogen- activated protein kinase signaling}

Dental pulp stem cells were lysed and the total protein was extracted using RIPA lysis buffer (Beyotime Biotechnology, Shanghai, China). Electrophoresis was performed on a $12 \%$ sodium dodecyl sulfate-polyacrylamide gel loaded with $20 \mu \mathrm{g}$ of total protein. The proteins were then transferred to a nitrocellulose membrane, followed by blocking with $5 \%$ defatted milk at $4{ }^{\circ} \mathrm{C}$ overnight. Subsequently, the membrane was washed with PBS and incubated with primary antibodies (anti-p38 and anti-phosphorylated p38, 2000× dilution; anti-ERK1/2 and anti-phosphorylated ERK1/2, 1000× dilution; anti-ACTIN, 1000× dilution), and consecutively with peroxidase-conjugated secondary antibodies - goat anti-mouse immunoglobulin G (IgG), diluted 1:5000 (Santa Cruz Biotechnology, Santa Cruz, USA). Chemiluminescence reagents (Thermo Fisher Scientific) were used to visualize the proteins, and the protein bands were exposed onto an X-ray film in a darkroom. Beta-actin served as an endogenous control.

Table 1. Primers used in the study

\begin{tabular}{|c|c|c|c|c|}
\hline Gene name & Forward $\left(5^{\prime}-3^{\prime}\right)$ & Reverse $\left(5^{\prime}-3^{\prime}\right)$ & Temperature $\left[{ }^{\circ} \mathrm{C}\right]$ & Product [bp] \\
\hline CD73 & AGCAGCATTCCTGAAGATCCA & TTCCAGAACATTTCATCCGTGT & 59 & 212 \\
\hline CD90 & GATCCTAGCCTCACCCGTCA & TGTTTTTTGCAGCCTTGGCT & 60 & 228 \\
\hline CD166 & GATACCATTATCATACCTTGCCG & CTGTCTTCTGAAATGCAGTCACC & 60 & 377 \\
\hline CD14 & TCATCAGGACACTGCCAGGA & GCTTCCAGGCTTCACACTTG & 60 & 240 \\
\hline CD34 & CTTGGAAGTACCAGCCTGCA & AGGCAGATGCCCTGAGTCAA & 60 & 374 \\
\hline IL-1 & TGAGCTCGCCAGTGAAATGA & CATGGCCACAACAACTGACG & 59 & 199 \\
\hline $\operatorname{lL}-4$ & GTGCACCGAGTTGACCGTA & CGTACTCTGGTTGGCTTCCT & 58 & 256 \\
\hline IL-6 & TCAATATTAGAGTCTCAACCCCCA & AGAAGGCAACTGGACCGAAG & 60 & 161 \\
\hline$I L-1 \beta$ & CCTGAGCTCGCCAGTGAAAT & CATGGCCACAACAACTGACG & 60 & 201 \\
\hline IFN- $\gamma$ & GCAGCTAAAACAGGGAAGCG & CTTGCTTAGGTTGGCTGCCT & 60 & 349 \\
\hline TNF- $a$ & CTGGGCAGGTCTACTTTGGG & CTGGAGGCCCCAGTTTGAAT & 60 & 272 \\
\hline VEGF & CTCACCAAGGCCAGCACATA & GGCTCCAGGGCATTAGACAG & 60 & 201 \\
\hline GAPDH & TTGTCATCAATGGAAATCCCAT & CCAGTAGAGGCAGGGATGATGT & 60 & 436 \\
\hline
\end{tabular}

IL - interleukin; IFN- $\gamma$ - interferon-gamma; TNF- - tumor necrosis factor-alpha; VEGF - vascular endothelial growth factor;

GAPDH - glyceraldehyde 3-phosphate dehydrogenase. 
A

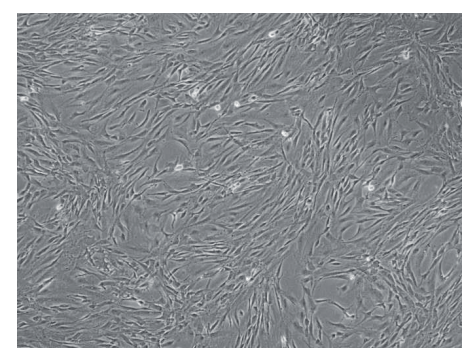

B

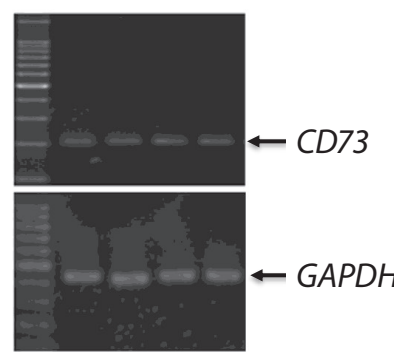

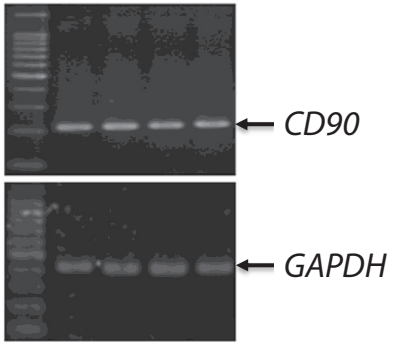

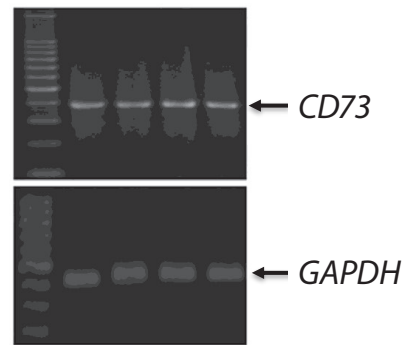

Fig. 1. Characterization of isolated DPSCS

A) morphological analysis of DPSCs; B) expression of mesenchymal markers in DPSCs. DPSCs - dental pulp stem cells; GAPDH - glyceraldehyde 3-phosphate dehydrogenase; GAPDH was used as an endogenous control; experiments were carried out in 4 independent trials.

\section{Statistical analysis}

SPSS v. 19.0 software (IBM Corp., Armonk, USA) was used for the statistical analysis. After confirming a normal distribution, the data was presented as means \pm standard deviation (SD). A 2-tailed t-test was performed to compare the means between the 2 groups. One asterisk (*) indicates a statistical difference complying with $\mathrm{p}<0.05$, and 2 asterisks $\left({ }^{*} *\right)$ indicate $\mathrm{p}<0.01$.

\section{Results}

\section{Characterization of isolated dental pulp stem cells}

The cells from the dental pulp were isolated and cultivated in cell dishes. These cells showed the typical morphology of mesenchymal stem cells (MSCs) (Fig. 1A). To determine whether these cells were mesenchymal, the cell surface markers considered important stemness determinants associated with DPSCs - CD73, CD90 and CD166 - were characterized. ${ }^{20}$ In Fig. 1B, these 3 molecules were depicted as highly expressed by using the reverse transcription PCR (RT-PCR) method. Meanwhile, the hematopoietic markers CD14 and CD34 were also examined. A negative expression was observed (data not shown). These results proved that DPSCs were successfully isolated and could be used in further research.

\section{Simvastatin-promoted proliferation of dental pulp stem cells}

To explore the effects of simvastatin on the viability of DPSCs, the cells were cultured with gradient concentrations of simvastatin ranging from 0 to $20 \mu \mathrm{g} / \mathrm{mL}(0,2,4,8,10,15$, and $20 \mu \mathrm{g} / \mathrm{mL}$ ) and a Cell-Counting Kit-8 (CCK-8) (Sigma-Aldrich) assay was performed. It was observed that cells challenged with a low concentration of simvastatin $(2,4,8$, or $10 \mu \mathrm{g} / \mathrm{mL})$ propagated faster than untreated ones. High concentrations (15 and $20 \mu \mathrm{g} / \mathrm{mL}$ ), however, reduced proliferation. Importantly, $8 \mu \mathrm{g} / \mathrm{mL}$ of simvastatin induced the fastest cell growth (Fig. 2A).
Lipopolysaccharides were considered to be a potent inducer of pulpitis, and they were also reported to inhibit the proliferation of DPSCs. ${ }^{21,22}$ Here we investigated whether simvastatin could promote cell proliferation under the conditions of LPS challenging. Compared to the controls, DPSCs treated with $60 \mu \mathrm{g} / \mathrm{mL}$ of LPS showed inhibited proliferation, whereas simvastatin $(8 \mu \mathrm{g} / \mathrm{mL})$ restored a high growth rate in the LPS + simvastatin group (Fig. $2 \mathrm{~B})$. These results indicated that simvastatin could stimulate the proliferation of DPSC under both normal and inflammatory conditions.
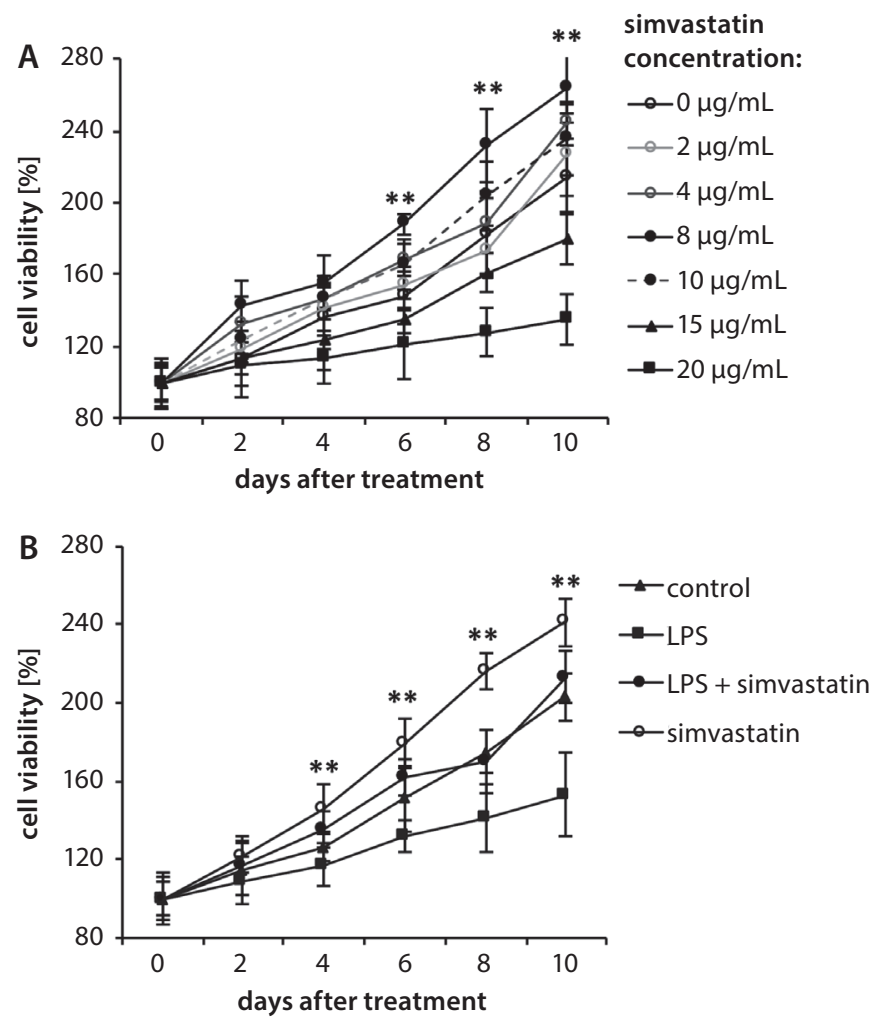

Fig. 2. Analysis of cell viability of DPSCS

A) proliferation of DPSCs treated with different concentrations of simvastatin; ** $\mathrm{p}<0.01$; cell exposure to $8 \mu \mathrm{g} / \mathrm{mL}$ vs $0 \mu \mathrm{g} / \mathrm{mL}$ of simvastatin; B) proliferation of DPSC s treated with LPS or simvastatin; ** $p<0.01$; LPS + simvastatin group vs LPS group. DPSCs - dental pulp stem cells; LPS - lipopolysaccharides. 
A

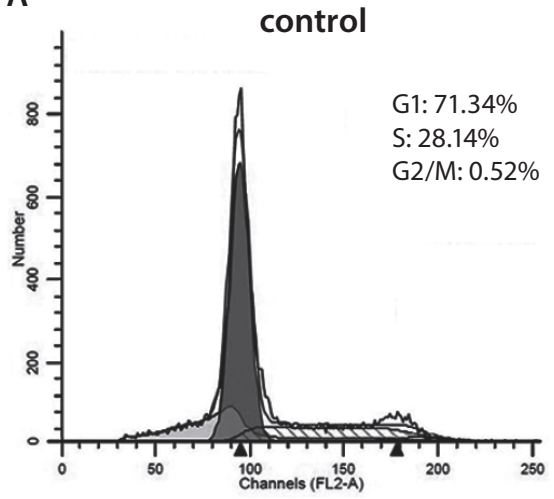

LPS

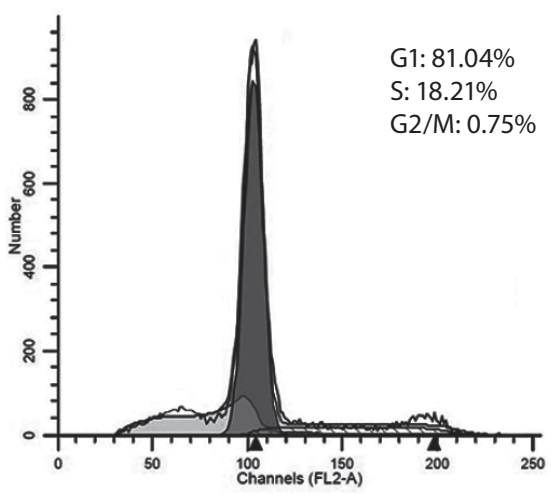

B

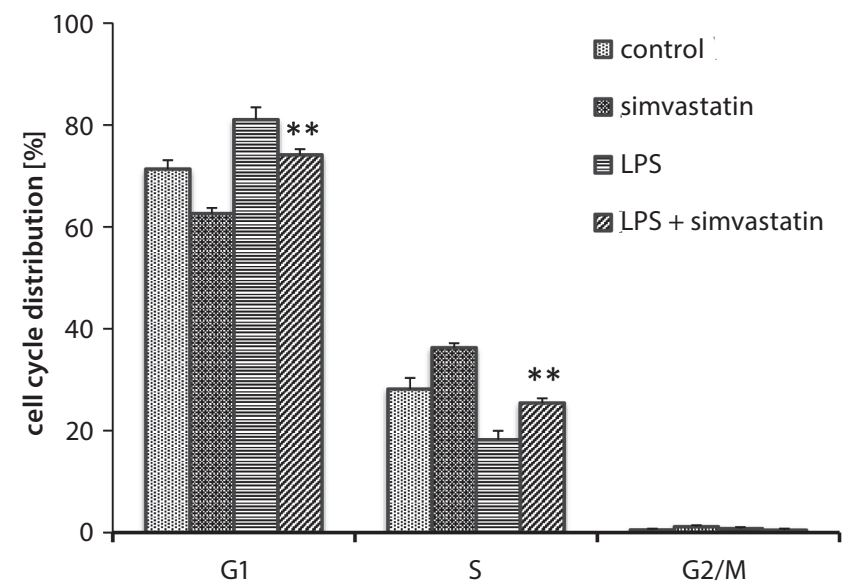

\section{Simvastatin-promoted cell cycling}

In order to investigate the effects of simvastatin on the cell cycling progression of DPSCs, flow cytometry was performed to measure the distributions of each phase. Figure 3B illustrates the mean percentage values of cycling phases in cells treated with LPS or simvastatin. The proportion of the G1 population increased from $71.34 \pm 1.76 \%$ of the control group to $81.04 \pm 2.43 \%$ of the LPS group, while it fell back to $74.12 \pm 1.12 \%$ of the LPS + simvastatin group. These results indicate that LPS arrested DPSCs at the G1 phase, while simvastatin promoted cell cycling progression to the $S$ phase. simvastatin

1: $62.60 \%$

S: $36.26 \%$

G2/M: $1.14 \%$

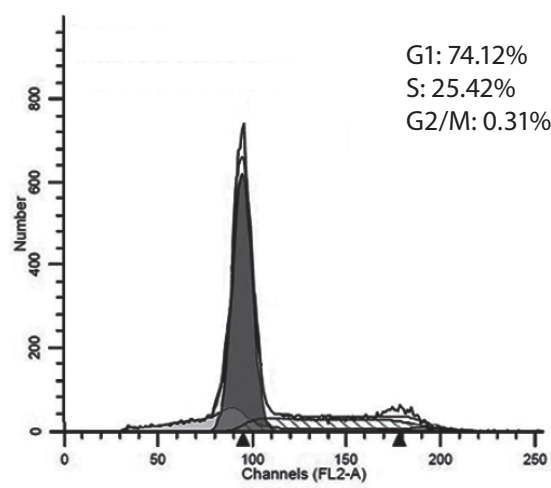

Fig. 3. Effects of simvastatin on cell cycling progression of DPSCs

A) flow cytometry graphs in cells treated with LPS or simvastatin; B) mean values of different cycle phases in untreated cells, cells treated with simvastatin, with LPS, and with LPS + simvastatin; ** $p<0.01$; LPS + simvastatin group vs LPS group; $n=6$. DPSCs - dental pulp stem cells; LPS - lipopolysaccharides.

\section{Simvastatin-promoted apoptosis}

In order to further characterize the effect of simvastatin on the apoptosis of DPSCs, flow cytometry analysis was performed using Annexin V-FITC and PI to differentiate cells undergoing apoptosis or necrosis. As shown in Fig. 4, cells died in response to LPS treatment $(8.74 \pm 2.4 \%$ in the LPS group vs $2.49 \pm 1.3 \%$ in the control group). Simvastatin caused a slight increase in the number of apoptotic cells compared to the control group ( $\mathrm{p}>0.05$ ). However, in combination with LPS challenging, there was a significantly elevated rate of apoptosis $(\mathrm{p}<0.01)$. This data demonstrates that simvastatin promotes the apoptosis of DPSCs in LPS stimulation.

\section{Simvastatin-suppressed inflammatory response}

The inflammatory response in the dental pulp is mediated by various cytokines, including IL- 1 , IL-4, IL-6, IL-1 $\beta$, IFN- $\gamma$, and TNF- $\alpha .^{23}$ The expression of these genes was quantified 

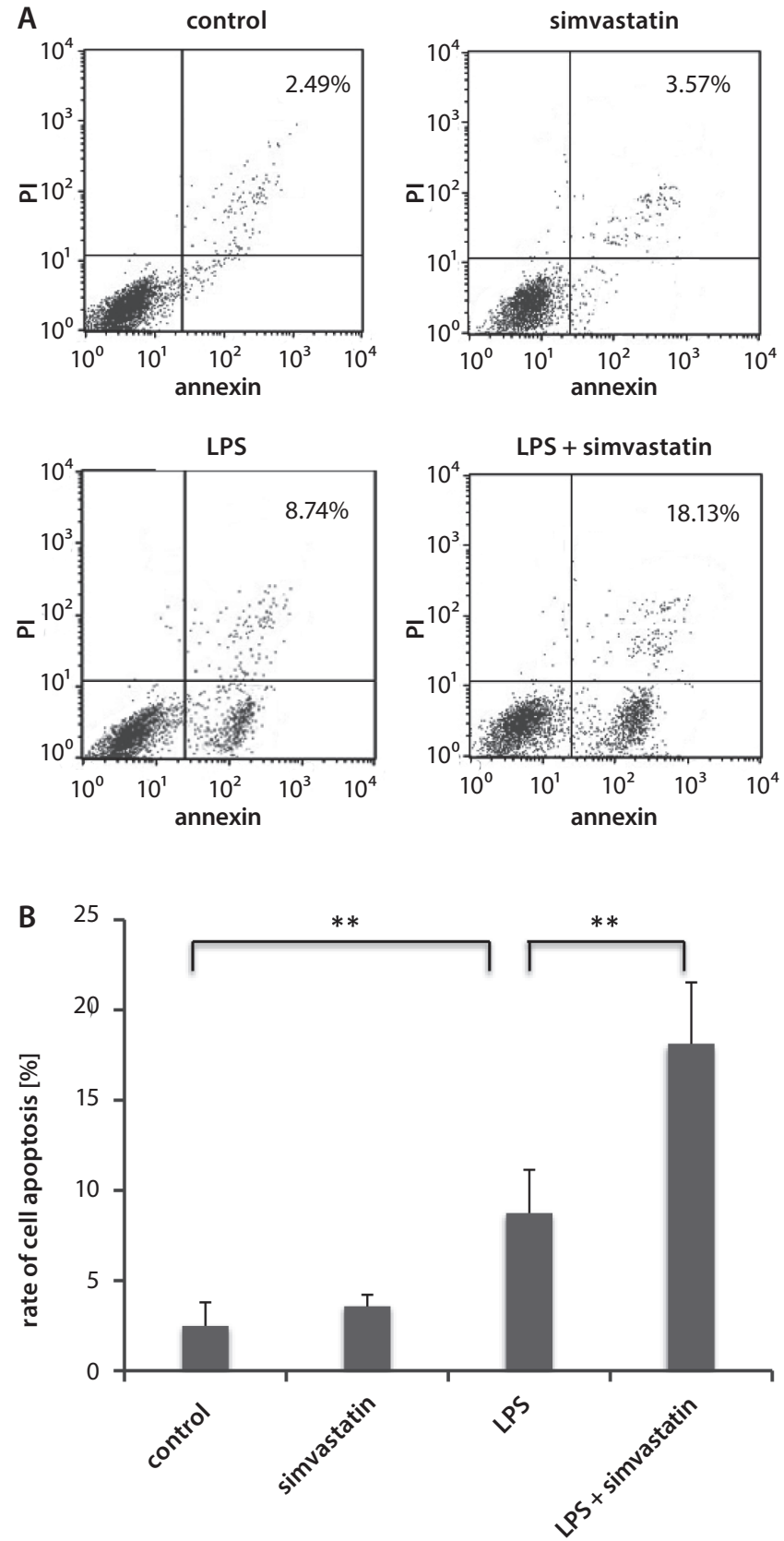

Fig. 4. Effects of simvastatin on cell apoptosis of DPSCs

A) flow cytometry graphs in cells treated with LPS or simvastatin; B) mean values of apoptosis rate in untreated cells, cells treated with simvastatin, with LPS, and with LPS + simvastatin; ** $p<0.01 ; n=6$. DPSCs - dental pulp stem cells; LPS - lipopolysaccharides;

$\mathrm{PI}$ - propidium iodide.

by $\mathrm{qPCR}$ and it was found that LPS induced the upregulated expression of $I L-1, I L-4, I L-6, I L-1 \beta, I F N-\gamma$, and TNF- $\alpha$, of which $I L-1 \beta$ and $T N F-\alpha$ exhibited the highest alterations, with fold changes of 7.84 and 12.17, respectively. By contrast, simvastatin suppressed the genes of increased expression, except for $I L-6$. Compared to the LPS group, the exposure to simvastatin caused a 3.2-fold decrease of $I L-1 \beta$ expression and a 3.5-fold decrease of TNF- $\alpha$ (Fig. 5). The decreased expression of cytokines indicates that simvastatin suppressed the inflammatory response in inflamed DPSCs.

\section{Simvastatin-downregulated vascular endothelial growth factor expression via inhibiting p38 mitogen-activated protein kinase signaling}

During pulpitis, angiogenic growth factor is the crucial element for vasculogenesis, as well as a part of the associated inflammation. ${ }^{24}$ Among various factors, the most potent is VEGF, which is responsible for angiogenesis and the development and permeation of new blood vessels. ${ }^{25}$ In this study, we evaluated the effects of LPS and simvastatin on VEGF production. The secretion of VEGF was determined by ELISA. Simvastatin dramatically suppressed VEGF secretion, induced by LPS. A reduction was also observed in the expression of the VEGF gene (Fig. 6A).

VEGF expression was demonstrated to be induced by LPS, depending on mitogen-activated protein kinase (MAPK) activation. ${ }^{26}$ To reveal the pathway on which simvastatin attenuated VEGF expression, we examined the activity of MAPK signaling by western blot. Lipopolysaccharides were found to increase the phosphorylation levels of P38 and ERK1/2, in line with a previous study. ${ }^{26}$ Of note, simvastatin markedly decreased P38 and ERK1/2 phosphorylation in both control and LPS-treated cells (Fig. 6B). These results indicate that simvastatin attenuates VEGF expression via blocking p38 MAPK signaling.

\section{Discussion}

Dental pulp stem cells are regarded as a subpopulation of MSCs, possessing the property of self-renewal, the expression of multiple MSC surface markers, and differentiation into various cell types, such as odontoblasts, adipocytes, cardiomyocytes, osteoblasts, chondrocytes, liver cells, etc. ${ }^{27}$ Their natural capacity for producing odontoblasts to create reparative dentin attracts researchers for applications in the regeneration of tooth structures. In vitro studies showed that DPSCs played important role in the dentin/pulp complex generation and immunoregulation. ${ }^{28,29}$ Dental pulp stem cells can be readily isolated from the healthy dental pulp tissue of human impacted $3^{\text {rd }}$ molars, which are naturally lost during childhood or removed during routine dental procedures. ${ }^{30}$ Considering the superior property and convenient handling, DPSCs are considered a valuable source of cells utilized in regenerative therapies for various diseases, including dental pulp regeneration, tooth reconstruction, bone tissue engineering, and other applications in cell therapy. ${ }^{7}$

Dental pulp stem cells are able to respond to specific extracellular excitatory signals and play a crucial role in dentin regeneration after injury in acute and chronic pulpitis. ${ }^{10}$ Simvastatin, a semisynthetic lipophilic 3-hydroxy-3-methylglutaryl-coenzyme A reductase (HMGCR) inhibitor, was extensively used as a well-established cholesterol-lowering drug, able to inhibit cholesterol synthesis, and showed 

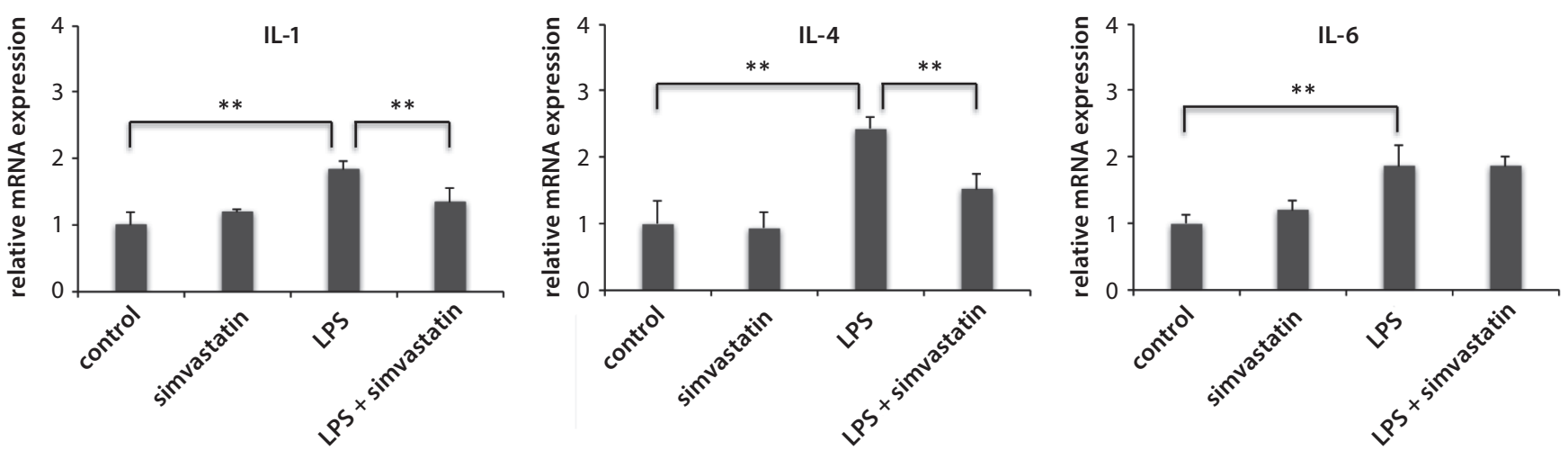

IL-1 $\beta$
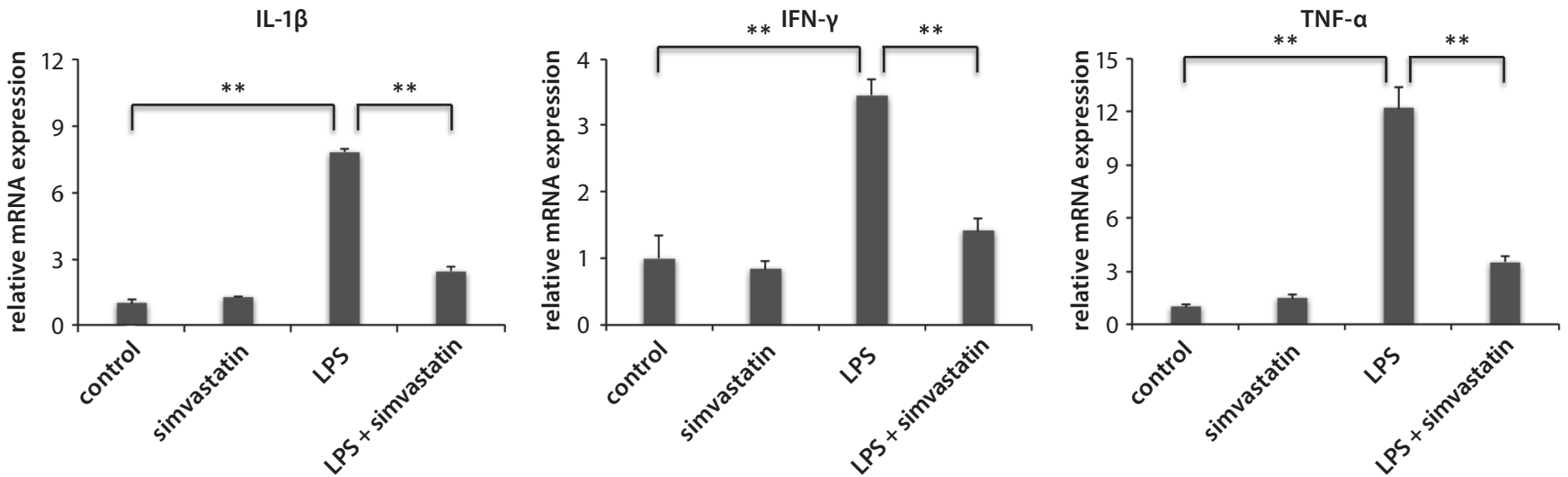

Fig. 5. Expression of cytokines treated with LPS or simvastatin

LPS - lipopolysaccharides; IL - interleukin; IFN- - - interferon-gamma; TNF-a - tumor necrosis factor-alpha; GAPDH - glyceraldehyde 3-phosphate dehydrogenase; experiments were carried out in triplicate; gene expression was normalized by GAPDH; ** $p<0.01$.
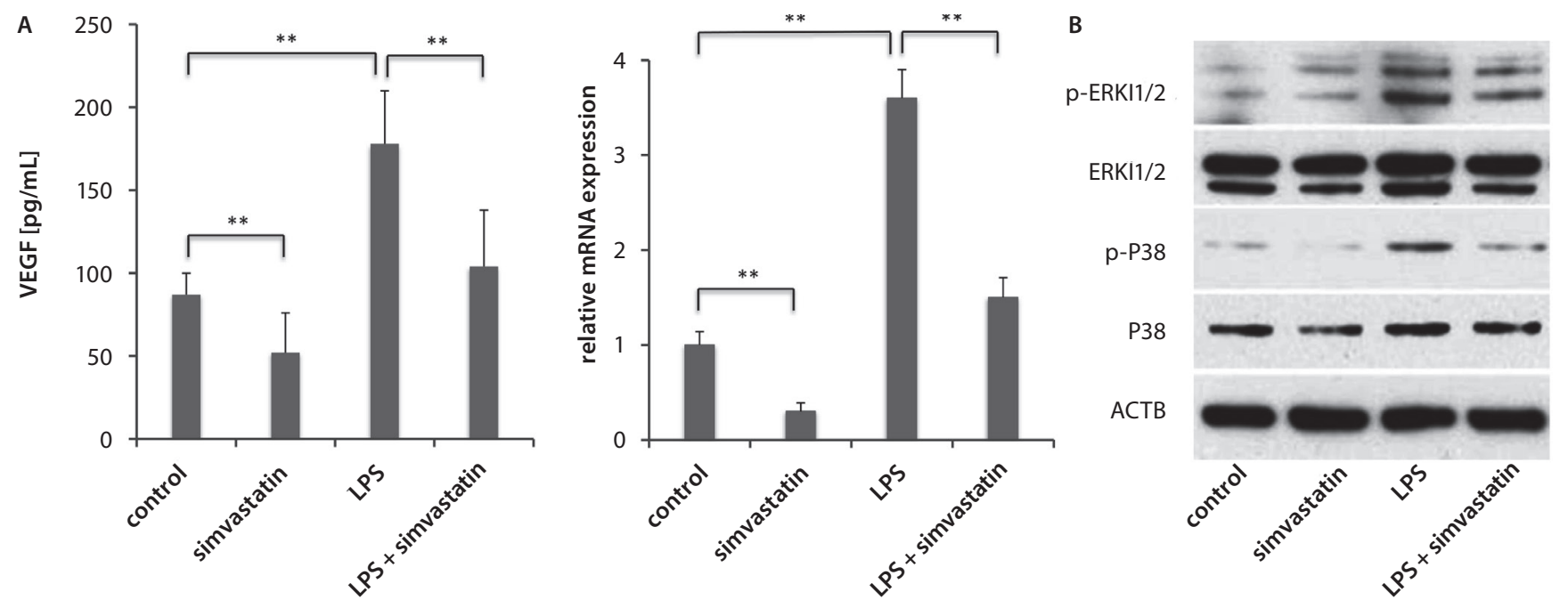

Fig. 6. Effects of simvastatin on VEGF expression

A) simvastatin decreased VEGF secretion (left) and gene expression (right); B) simvastatin-inhibited phosphorylation of p38 and ERK1/2 in MAPK signaling examined by western blot; VEGF - vascular endothelial growth factor; MAPK - mitogen-activated protein kinase; LPS - lipopolysaccharides; $p$ - phosphorylation; ACTB - $\beta$-actin; ACTB was used as an internal control; experiments were run in triplicate; ${ }^{* *} p<0.01$.

potent effects on cell proliferation, cell cycling and apoptosis. ${ }^{31,32}$ Besides, simvastatin was demonstrated to be able to induce human DPSCs differentiation into odontoblasts and to promote pulp regeneration. ${ }^{15,16}$ This study was aimed at investigating how simvastatin affects DPSCs under the conditions of inflammation caused by LPS.
The results showed that low concentrations of simvastatin accelerated the proliferation of DPSCs, while high concentrations of simvastatin $(>15 \mu \mathrm{g} / \mathrm{mL})$ exhibited a suppressive effect. Treatment with LPS also inhibited cell growth, and combinatory stimulation with simvastatin recovered a high proliferation rate. Furthermore, we performed 
fluorescence-activated cell sorting (FACS) to characterize the cell cycling and apoptosis in DPSCs treated with simvastatin or LPS, and found that simvastatin promoted cell cycling into phase $S$, and induced apoptosis as well. These results collectively indicate that simvastatin enhances the proliferation of DPSCs by promoting cell cycling progression and apoptosis (Fig. 2-4).

An inflammatory response is very common during pulpitis caused by carious bacteria and their products, and is mediated by cytokines, such as IL-1, IL-4, IL-6, IL-1 $\beta$, IFN- $\gamma$, and TNF- $\alpha .{ }^{23}$ Mesenchymal stem cells, including DPSCs, have the capacity to receive inflammatory signals and to express a large number of cytokines. Conversely, chronic exposure to these cytokines potentially affects the activity of DPSCs, leading to impairment in immunomodulatory and anti-inflammatory roles, and to suppression of the differentiation ability of DPSCs. ${ }^{33,34}$ In our study, we observed that simvastatin suppressed the expression of the examined cytokines, with the highest alterations in $I L-1 \beta$ and TNF- $\alpha$ (Fig. 5), suggesting that simvastatin was capable of relieving the inflammatory response. In a previous study, TNF- $\alpha$ was found to stimulate the proliferation of DPSCs by regulating the Akt/GSK-3 $\beta /$ cyclin D1 signaling pathway. ${ }^{35}$ Lipopolysaccharides significantly promoted TNF- $\alpha$ expression (Fig. 5), while the growth rate of DPSCs was suppressed (Fig. 2B), inferring that some unknown factors (except for $T N F-\alpha$ ) affected cell proliferation.

Vascular endothelial growth factor has been found to be strongly expressed in teeth with irreversible pulpitis, and it can increase and extend the severity of the inflammatory processes because of an increased transport of nutrients, oxygen and inflammatory cells to the site of inflammation, and thus it affects dentinogenesis and progresses to necrosis. ${ }^{24,36}$ In in vitro cells, the upregulation of VEGF during inflammation was demonstrated to significantly contribute to the pathogenesis associated with the survival and differentiation of DPSCs. ${ }^{37}$ Expression of VEGF was previously shown to be induced through MAPK signaling, which was confirmed by the upregulated phosphorylation levels of P38 and ERK1/2 (Fig. 6B). ${ }^{26}$ Notably, our results also showed that in inflamed DPSCs, characterized by an elevated expression of various cytokines, augmented VEGF expression and secretion (Fig. 6A) were accompanied by decreased cell viability (Fig. 2). In contrast, simvastatin significantly inhibited VEGF synthesis and promoted cell proliferation. Considering the fact that VEGF was induced by MAPK signaling (Fig. 6B), it is rational to speculate that simvastatin counteracted the effects of LPS on VEGF expression and MAPK signaling, and thus enhanced the proliferation of DPSCs.

In conclusion, we found that simvastatin promoted cell proliferation, cell cycling and apoptosis in inflamed DPSCs induced by LPS. Moreover, the expression of multiple cytokines and VEGF was observed to be significantly inhibited. Vascular endothelial growth factor was demonstrated to be regulated through the blocking of MAPK signaling.
Collectively, simvastatin was shown to enhance cell viability, perhaps via the MAPK/VEGF axis, and to relieve inflammation response as well. This study provided some evidence to support the hypothesis that simvastatin might be a potent therapy for pulpitis.

\section{References}

1. Michaelson PL, Holland GR. Is pulpitis painful? Int Endod J. 2002;35(10):829-832.

2. Ahlquist ML, Franzen OG. Inflammation and dental pain in man. Endod Dent Traumatol. 1994;10(5):201-209.

3. Hahn CL, Liewehr FR. Relationships between caries bacteria, host responses, and clinical signs and symptoms of pulpitis. J Endod. 2007;33(3):213-219.

4. Khabbaz MG, Anastasiadis PL, Sykaras SN. Determination of endotoxins in caries: Association with pulpal pain. Int Endod J. 2000;33(2):132-137.

5. Jacinto RC, Gomes BP, Shah HN, Ferraz CC, Zaia AA, Souza-Filho FJ. Quantification of endotoxins in necrotic root canals from symptomatic and asymptomatic teeth. J Med Microbiol. 2005;54(Pt 8):777-783.

6. Liu H, Gronthos S, Shi S. Dental pulp stem cells. Methods Enzymol. 2006;419:99-113.

7. Tatullo M, Marrelli M, Shakesheff KM, White LJ. Dental pulp stem cells: Function, isolation and applications in regenerative medicine. J Tissue Eng Regen Med. 2015;9(11):1205-1216.

8. Na S, Zhang H, Huang F, et al. Regeneration of dental pulp/dentine complex with a three-dimensional and scaffold-free stem-cell sheetderived pellet. J Tissue Eng Regen Med. 2016;10(3):261-270.

9. Paino F, Ricci G, De Rosa A, et al. Ecto-mesenchymal stem cells from dental pulp are committed to differentiate into active melanocytes. Eur Cell Mater. 2010;20:295-305.

10. Ustiashvili M, Kordzaia D, Mamaladze M, Jangavadze M, Sanodze L. Investigation of functional activity human dental pulp stem cells at acute and chronic pulpitis. Georgian Med News.2014;234:19-24.

11. Fedorowicz Z, van Zuuren EJ, Farman AG, Agnihotry A, Al-Langawi JH. Antibiotic use for irreversible pulpitis. Cochrane Database Syst Rev. 2013;2:CD004969. doi: 10.1002/14651858.CD004969.pub4

12. Hoskin E, Veitz-Keenan A. Antibiotics are not useful to reduce pain associated with irreversible pulpitis. Evid Based Dent. 2016;17(3):81-82.

13. Iohara $K$, Nakashima $M$, Ito $M$, Ishikawa $M$, Nakasima A, Akamine A. Dentin regeneration by dental pulp stem cell therapy with recombinant human bone morphogenetic protein 2. J Dent Res. 2004;83(8):590-595.

14. Saito T, Ogawa M, Hata $Y$, Bessho K. Acceleration effect of human recombinant bone morphogenetic protein-2 on differentiation of human pulp cells into odontoblasts. J Endod. 2004;30(4):205-208.

15. Karanxha L, Park SJ, Son WJ, Nor JE, Min KS. Combined effects of simvastatin and enamel matrix derivative on odontoblastic differentiation of human dental pulp cells. J Endod. 2013;39(1):76-82.

16. Okamoto Y, Sonoyama W, Ono M, et al. Simvastatin induces the odontogenic differentiation of human dental pulp stem cells in vitro and in vivo. J Endod. 2009;35(3):367-372.

17. Jia W, Zhao Y, Yang J, et al. Simvastatin promotes dental pulp stem cell-induced coronal pulp regeneration in pulpotomized teeth. J Endod. 2016;42(7):1049-1054.

18. Raoof M, Yaghoobi MM, Derakhshani A, et al. A modified efficient method for dental pulp stem cell isolation. Dent Res J (Isfahan). 2014;11(2):244-250.

19. Shi X, Gipp J, Dries M, Bushman W. Prostate progenitor cells proliferate in response to castration. Stem Cell Res. 2014;13(1):154-163.

20. Lee SY, Huang GW, Shiung JN, et al. Magnetic cryopreservation for dental pulp stem cells. Cells Tissues Organs. 2012;196(1):23-33.

21. Warfvinge J, Dahlen G, Bergenholtz G. Dental pulp response to bacterial cell wall material. J Dent Res. 1985;64(8):1046-1050.

22. Liu Y, Gao Y, Zhan X, et al. TLR4 activation by lipopolysaccharide and Streptococcus mutans induces differential regulation of proliferation and migration in human dental pulp stem cells. J Endod. 2014;40(9):1375-1381.

23. Hozhabri NS, Benson MD, Vu MD, et al. Decreasing NF-kappaB expression enhances odontoblastic differentiation and collagen expression in dental pulp stem cells exposed to inflammatory cytokines. PLoS One. 2015;10(1):e0113334. doi: 10.1371/journal.pone.0113334 
24. Guven G, Altun C, Gunhan O, et al. Co-expression of cyclooxygenase-2 and vascular endothelial growth factor in inflamed human pulp: An immunohistochemical study. J Endod. 2007;33(1):18-20.

25. Dvorak HF, Nagy JA, Feng D, Brown LF, Dvorak AM. Vascular permeability factor/vascular endothelial growth factor and the significance of microvascular hyperpermeability in angiogenesis. Curr Top Microbiol Immunol. 1999;237:97-132.

26. Botero TM, Son JS, Vodopyanov D, Hasegawa M, Shelburne CE, Nör JE. MAPK signaling is required for LPS-induced VEGF in pulp stem cells. J Dent Res. 2010;89(3):264-269.

27. Potdar PD, Jethmalani YD. Human dental pulp stem cells: Applications in future regenerative medicine. World J Stem Cells. 2015;7(5):839-851.

28. Batouli S, Miura M, Brahim J, et al. Comparison of stem-cell-mediated osteogenesis and dentinogenesis. J Dent Res. 2003;82(12):976-981.

29. Wada N, Menicanin D, Shi S, Bartold PM, Gronthos S. Immunomodulatory properties of human periodontal ligament stem cells. J Cell Physiol. 2009;219(3):667-676.

30. Gronthos S, Mankani M, Brahim J, Robey PG, Shi S. Postnatal human dental pulp stem cells (DPSCs) in vitro and in vivo. Proc Natl Acad Sci USA. 2000;97(25):13625-13630.
31. Afzali M, Vatankhah M, Ostad SN. Investigation of simvastatininduced apoptosis and cell cycle arrest in cancer stem cells of MCF-7. J Cancer Res Ther. 2016;12(2):725-730.

32. Wang G, Cao R, Wang Y, et al. Simvastatin induces cell cycle arrest and inhibits proliferation of bladder cancer cells via PPAR $y$ signalling pathway. Sci Rep. 2016;6:35783. doi: 10.1038/srep35783

33. Le Blanc K. Mesenchymal stromal cells: Tissue repair and immune modulation. Cytotherapy. 2006;8(6):559-561.

34. Sonoda S, Yamaza H, Ma L, et al. Interferon-gamma improves impaired dentinogenic and immunosuppressive functions of irreversible pulpitis-derived human dental pulp stem cells. Sci Rep. 2016;6:19286. doi: 10.1038/srep19286

35. Qin Z, Li Y, Li Y, Liu G. Tumor necrosis factor alpha stimulates proliferation of dental pulp stem cells via Akt/glycogen synthase kinase3beta/cyclin D1 signaling pathway. J Endod. 2015;41(7):1066-1072.

36. Chu SC, Tsai CH, Yang SF, et al. Induction of vascular endothelial growth factor gene expression by proinflammatory cytokines in human pulp and gingival fibroblasts. J Endod. 2004;30(10):704-707.

37. Matsushita K, Motani R, Sakuta T, et al. The role of vascular endothelial growth factor in human dental pulp cells: Induction of chemotaxis, proliferation, and differentiation and activation of the AP-1dependent signaling pathway. J Dent Res. 2000;79(8):1596-1603. 